\title{
KOMUNIKATOR TUNARUNGU DAN TUNANETRA
}

\author{
Syahrul ${ }^{1}$, Mochamad Fajar Wicaksono ${ }^{2}$ \\ 1,2 Jurusan Teknik Komputer, Fakultas Teknik dan Ilmu Komputer, Universitas Komputer Indonesia \\ Jl. Dipati Ukur No. 112-116, Bandung 40132 \\ Telepon (022) 2504119, 2503371, 2506634, Fax (022) 2533754 \\ e-mail: syahrulssyl@yahoo.com; fay.heartagram@gmail.com
}

Diterima: 16 Mei 2012 / Disetujui: 14 Juni 2012

\begin{abstract}
This paper describes the design and implementation of the deaf and blind communicator with the aim that they can communicate by using a Braille Codes per character and speech recognition using a computer. Communicator device is designed using AT89C51 microcontroller to change the characters that is sent by the computer into Braille code. The signal transmitted from the computer by hearing impairment through RS-232 serial interface with the help of driver IC ULN2803 to drive the solenoid. The end of the solenoid form a pattern of Braille code. Speech pattern recognition used are dictation mode with discrete speech method, whole word, large vocabulary and speaker dependent is designed with SAPI 5.1, Microsoft Speech Engine SDK 5.1 and Delphi software 6.0 to create an application program. On testing who performed indicate that the all the characters that is sent from keyboard can be converted become Braille Character who represented through the solenoid. While the recognition of sound patterns of the microphone most of the well can be translated into the characters displayed on a computer monitor. The success rate in speech recognition can be influenced by several factors such as differences in the sound at the time of training and at the time of dictation, noise from the environment and the quality of the microphone being used.
\end{abstract}

Keywords: communicator, deaf, blind, computer / microcontroller.

\begin{abstract}
ABSTRAK
Tulisan ini membahas perancangan dan implementasi komunikator penyandang tunarungu dan tunanetra dengan tujuan agar mereka dapat berkomunikasi dengan menggunakan alat bantu Kode Braille dan pengenalan suara per karakter menggunakan komputer. Perangkat komunikator ini dirancang menggunakan mikrokontroler AT89C51 untuk mengubah karakter yang dikirimkan oleh komputer menjadi kode Braille. Sinyal dikirimkan dari komputer oleh tunarungu melalui antarmuka serial RS-232 dengan bantuan driver IC ULN2803 untuk menggerakkan solenoid. Bagian ujung dari solenoid membentuk pola kode Braille. Pengenalan pola suara menggunakan mode diktasi yang dengan metode discrete speech, whole word, large vocabulary dan speaker dependant dirancang dengan SAPI 5.1, Microsoft Speech Engine SDK 5.1 dan software Dephi 6.0 untuk membuat program aplikasi. Pada pengujian yang dilakukan menunjukkan semua karakter yang dikirimkan dari keyboard komputer dapat diubah menjadi karakter Braille yang direpresentasikan melalui solenoid. Sedangkan pada pengenalan pola suara dari mikropon sebagian besar juga dapat diterjemahkan menjadi karakter yang ditampilkan pada monitor komputer. Tingkat keberhasilan pada pengenalan suara dapat dipengaruhi beberapa faktor, misalnya perbedaan suara pada saat melakukan pelatihan dan pada saat melakukan diktasi, noise dari lingkungan dan kualitas dari mikropon yang digunakan.
\end{abstract}

Kata kunci: komunikator, tunarungu, tunanetra, komputer/mikrokontroler. 


\section{PENDAHULUAN}

Komunikasi merupakan kebutuhan manusia yang mendasar, karena itu komunikasi tidak membatasi apakah seseorang itu normal atau cacad. Komunikasi antar manusia yang memiliki keterbatasan fisik sangat sulit dilakukan, khususnya antara penyandang cacat tunanetra dengan penyandang cacat tunarungu. Oleh karena itu, dibutuhkan suatu alat yang dapat membantu kedua penyandang cacat ini agar dapat berkomunikasi.

Pada tulisan ini dibahas tentang rancang bangun alat bantu komunikator yang ditujukan untuk para penyandang cacat tunanetra dan tunarungu agar dapat berkomunikasi satu sama lain dengan menggunakan teknik pengenalan pola suara per karakter dan menggunakan alat bantu kode braille.

Dari sisi tunarungu yang mengendalikan sebuah komputer akan mengirimkan karakter ASCII dari keyboard dan akan dikonversi menjadi kode braille pada sisi tunanetra. Sedangkan dari sisi tunanetra ke tunarungu akan dikirimkan suara per-karakter yang diucapkan diubah menjadi bentuk tulisan pada monitor komputer.

\section{Metode Penelitan}

Metode penelitan yang digunakan adalah metode perancangan dan implementasi. Sistem yang dikembangkan adalah Alat Bantu Komunikator Tunarungu dan Tunanetra. Penelitian ini merupakan pengembangan dari tulisan yang sebelumnya telah dimuat pada "Prosiding Seminar Nasional Aplikasi Teknologi Informasi-SNATI 2009 ISSN: 1907-5022 dengan judul "Braille Code Trainer"

Perangkat komunikator ini dirancang menggunakan mikrokontroler AT89C51 untuk mengkonversi karakter yang dikirimkan oleh komputer menjadi kode Braille. Antarmuka yang digunakan adalah serial RS-232 dengan bantuan driver IC ULN2803 untuk menggerakkan solenoid. Solenoid berfungsi untuk membuat pola kode Braille. Pengenalan pola suara menggunakan mode diktasi yang dengan metode discrete speech, whole word, large vocabulary dan speaker dependant dirancang dengan SAPI 5.1, Microsoft Speech Engine SDK 5.1 dan program Dephi 6.0 untuk membuat aplikasi. Pembahasan teoritis mengenai Kode Braille, mikrokontroler AT89C51, solenoide, dan driver ULN 2803 akan disertakan berikut ini.

\section{Kode Braille}

Kode Braille adalah sejenis sistem tulisan sentuh yang digunakan oleh penyandang cacat tunanetra. Sistem ini awalnya dirancangkan oleh seorang perancis yang bernama Louis Braille yang buta sejak kecil. Ketika berusia 15 tahun, braille mengubah bentuk tulisan latin yang biasa dikenal menjadi bentuk tulisan yang biasa digunakan tentara untuk memudahkan membaca dalam gelap. Sistem ini dinamakan sistem braille. Dengan tujuan untuk mendapatkan kemudahan dalam membaca itulah Louis Braille menciptakan format tulisan yang disebut tulisan braille. Namun ketika itu braille tidak mempunyai huruf $\mathrm{W}$, tetapi sekarang braille sudah mempunyai huruf W.

Ada beberapa versi tulisan braille yang dikembangkan oleh beberapa negara diantaranya:

- Standard Braille

- American Modified Braille

- ISO8859-1 Braille

- Russian Braille

- Greek Braille

- Hebrew Braille

- Arab Braille

- Japanese Braille

- Korean Braille

- Chinese Braille

- Braille ASCII 
- Unicode

Selain standar braille umumnya versi-versi di atas memiliki perbedaan dalam hal (1) Membedakan antara huruf besar dan huruf kecil (dalam satu blok), (2) Membedakan antara huruf dan angka (dalam satu blok), (3) Banyaknya jenis karakter yang dapat diterjemahkan ke dalam kode braille, (4) Jumlah dot yang digunakan (untuk standar braille menggunakan 6 dot tetapi ada versi lain yang ada menggunakan 8 dot).

Untuk pembuatan alat ini penerjemahan dari tulisan latin manjadi Kode Braille yang penulis gunakan adalah versi Standard Braille seperti yang ditunjukkan pada Gambar 1.

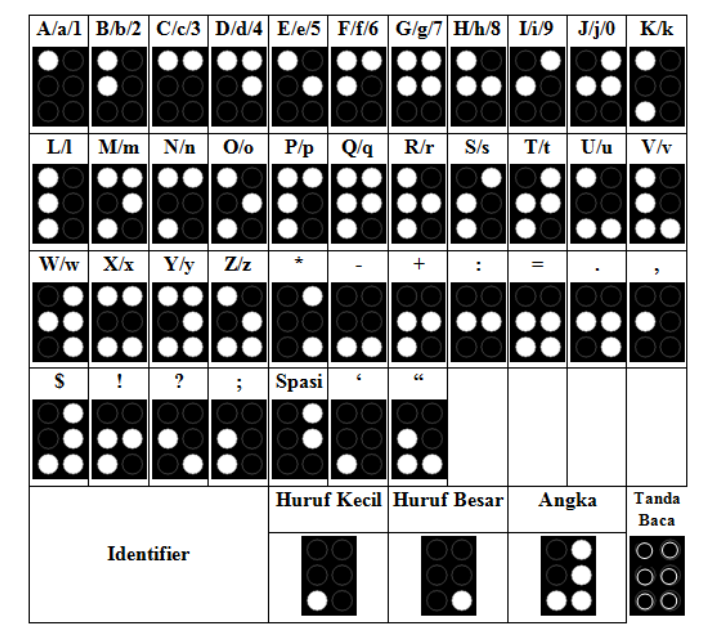

Gambar 1. Konversi huruf latin ke kode braille

\section{Solenoid dan Driver ULN2803}

Untuk menggerakan solenoid diperlukan sebuah driver. Driver diperlukan karena arus yang keluar dari mikrokontroler kecil, sehingga perlu dikuatkan. Rangkaian penggerak yang dirancang ini menggunakan dua buah driver di mana masing-masing driver digunakan untuk menggerakkan enam buah solenoid. Driver yang digunakan dalam pembuatan sistem alat bantu baca ini adalah IC ULN2803 dan arus keluaran pada setiap chanel-nya sebesar 500mA. Pada Gambar 3 diperlihatkan sirkuit ekivalen sebuah driver ULN2803.

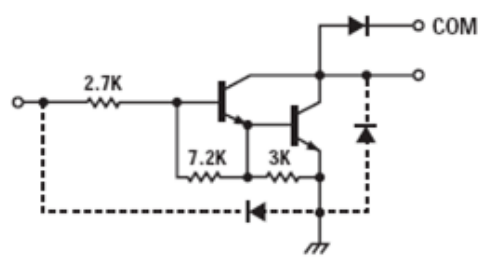

Gambar 3. Sirkuit Ekivalen Driver ULN2803 Menggunakan Konfigurasi Transistor Darlington

\section{Port Serial}


Pemanfaatan port serial sebagai jalur komunikasi antara alat bantu baca tuna netra dengan komputer karena tidak diperlukan banyak kabel untuk transmisi dibanding dengan port paralel. Selain itu pembuatan program juga lebih sederhana dan pengkabelannya lebih panjang. Pada Gambar 4 ditunjukkan sirkuit adaptor RS 232.

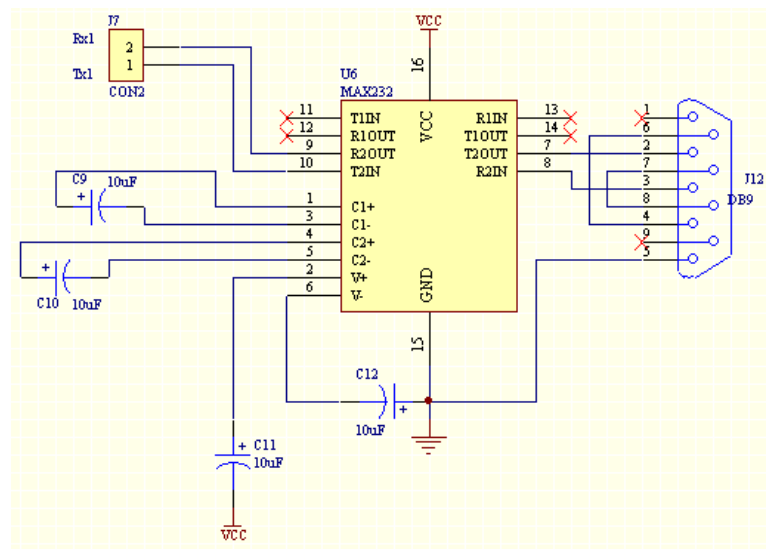

Gambar 4. Sirkuit Adaptor serial RS 232

Untuk komunikasi serial antara komputer dan mikrokontroler pada skema Gambar 4 digunakan IC MAX232. Pin-pin yang digunakan untuk pengiriman dan penerimaan data dalam perancangan alat ini adalah pin 8 (R2IN) untuk menerima data dari PC yang selanjutnya akan dikirimkan ke mikrokontroler malalui pin 9 (R2OUT) dan pin 10 (T2IN) digunakan untuk menerima data dari mikrokontroler yang selanjutnya akan dikirimkan ke komputer melalui pin 7 (T2OUT).

\section{HASIL DAN PEMBAHASAN}

Pada bagian ini dibahas realisasi dan hasil pengujian sistem. Realisasi sistem dilakukan dengan menggabungkan semua sub-modul hasil rancangan yang telah dibahas di atas. Pengujian dilakukan berdasarkan prosedur yang sudah baku, misalnya dilakukan pengukuran atau uji-coba terhadap modulmudul yang terpisah (sub-modul). Baru setelah semua sub-modul sudah sesuai dengan yang diharapkan maka dilakukanlah interkoneksi antara sub-modul lainnya yang pada akhirnya akan membentuk sistem yang lengkap. 


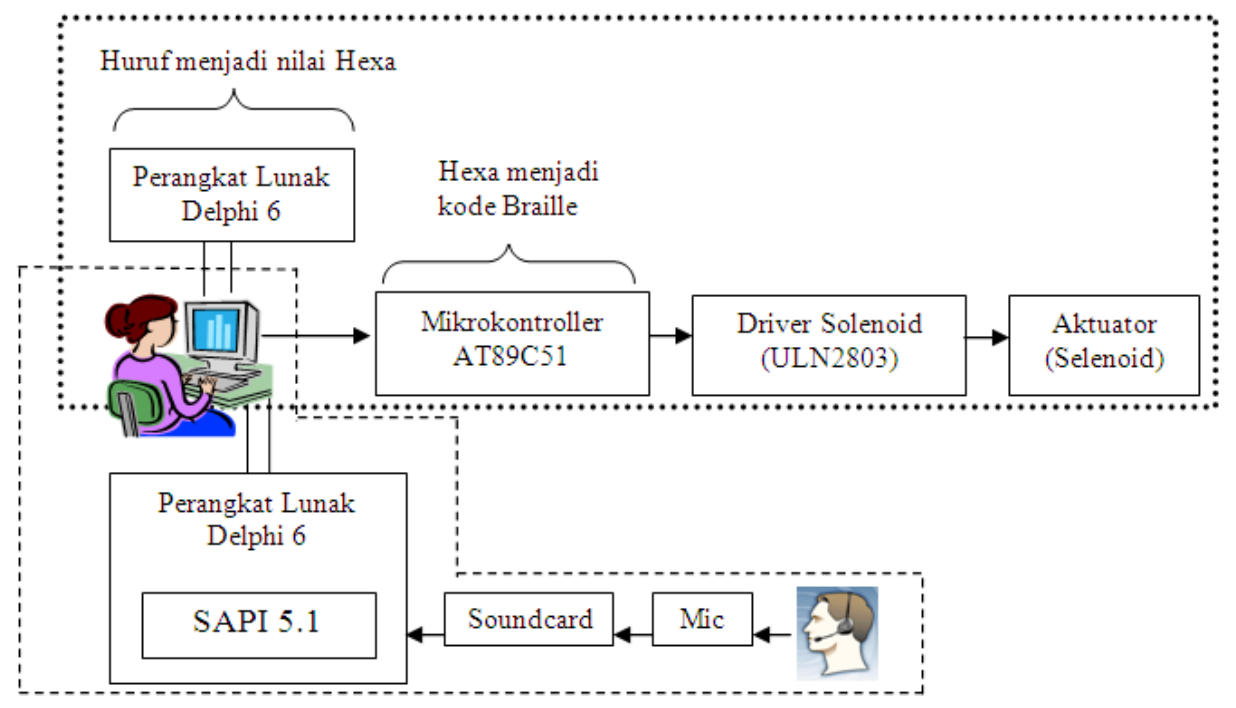

Gambar 5. Diagram Blok Rancangan Hardware Sistem

Pengukuran/pengujian yang paling akhir memeriksa apakah modul dapat berfungsi dengan baik. Selanjutnya memastikan tombol pada keyboard yang ditekan memberikan kode braille yang benar pada papan kode yang telah disediakan. Pengujian juga memastikan apakah suara dari mikropon ke sisi komputer dapat diterjemahkan menjadi karakter yang akan ditampilkan di monitor komputer.

\section{Rancangan Hardware Sistem}

Diagram blok Rancangan Hardware Sistem yang dibuat dapat dilihat pada Gambar 5. Spesifikasi Teknis hardware dan software sistem:

- Komputer dengan spesifikasi minimal Pentium dengan sistem operasi Windows

- Program aplikasi untuk komputer dibangun menggunakan bahasa pemrograman tingkat tinggi Delphi 6.0.

- Mikrokontroler AT89C51 dengan perangkat lunak assembly programming

- Pengantarmukaan hardware dengan komputer melalui serial port RS-232.

- Solenoida sebagai aktuator.

- ULN2803 sebagai driver yang menggerakan solenoida.

\section{Konversi ASCII menjadi Kode Braille}

Konversi karakter ASCII menjadi kode Braille didesain dengan cara mengubah setiap ekivalen heksadesimal kode ASCII 7 bit menjadi kode heksadesimal 6 bit yang setara Kode Braille sesuai dengan bentuk huruf Braille standard dan urutan pada perancangan solenoid yang dibuat.

Tabel 3. Konversi Kode ASCII ke Kode Braille Hexa 


\begin{tabular}{|c|c|c|c|}
\hline No. & Karakter & ASCII & Braille \\
\hline 1 & Spasi & $20 \mathrm{H}$ & $18 \mathrm{H}$ \\
\hline 2 & $!$ & $21 \mathrm{H}$ & $16 \mathrm{H}$ \\
\hline 3 & $"$ & $22 \mathrm{H}$ & $00 \mathrm{H}$ \\
\hline 4 & $\$$ & $24 \mathrm{H}$ & $3 \mathrm{CH}$ \\
\hline 5 & $*$ & $2 \mathrm{AH}$ & $28 \mathrm{H}$ \\
\hline 6 & + & $2 \mathrm{BH}$ & $16 \mathrm{H}$ \\
\hline 7 & , & $2 \mathrm{CH}$ & $02 \mathrm{H}$ \\
\hline 8 & - & $2 \mathrm{DH}$ & $24 \mathrm{H}$ \\
\hline 9 & . & $2 \mathrm{EH}$ & $32 \mathrm{H}$ \\
\hline 10 & 0 & $30 \mathrm{H}$ & $01 \mathrm{H}$ \\
\hline 11 & 1 & $31 \mathrm{H}$ & $03 \mathrm{H}$ \\
\hline 12 & 2 & $32 \mathrm{H}$ & $09 \mathrm{H}$ \\
\hline 13 & 3 & $33 \mathrm{H}$ & $19 \mathrm{H}$ \\
\hline 14 & 4 & $34 \mathrm{H}$ & $11 \mathrm{H}$ \\
\hline 15 & 5 & $35 \mathrm{H}$ & $0 \mathrm{BH}$ \\
\hline 16 & 6 & $36 \mathrm{H}$ & $1 \mathrm{BH}$ \\
\hline 17 & 7 & $37 \mathrm{H}$ & $13 \mathrm{H}$ \\
\hline 18 & 8 & $38 \mathrm{H}$ & $0 \mathrm{AH}$ \\
\hline 19 & 9 & $39 \mathrm{H}$ & $1 \mathrm{AH}$ \\
\hline 20 & : & $3 \mathrm{AH}$ & $26 \mathrm{H}$ \\
\hline 21 & ; & $3 \mathrm{BH}$ & $06 \mathrm{H}$ \\
\hline 22 & $=$ & $3 \mathrm{DH}$ & $30 \mathrm{H}$ \\
\hline 23 & $?$ & $3 \mathrm{FH}$ & $26 \mathrm{H}$ \\
\hline
\end{tabular}

\begin{tabular}{|c|c|c|c|}
\hline No. & Karakter & ASCII & Braille \\
\hline 39 & $\mathrm{P}$ & $50 \mathrm{H}$ & $0 \mathrm{FH}$ \\
\hline 40 & Q & $51 \mathrm{H}$ & $1 \mathrm{FH}$ \\
\hline 41 & $\mathrm{R}$ & $52 \mathrm{H}$ & $17 \mathrm{H}$ \\
\hline 42 & S & $53 \mathrm{H}$ & $0 \mathrm{EH}$ \\
\hline 43 & $\mathrm{~T}$ & $54 \mathrm{H}$ & $1 \mathrm{EH}$ \\
\hline 44 & $\mathrm{U}$ & $55 \mathrm{H}$ & $25 \mathrm{H}$ \\
\hline 45 & $\mathrm{~V}$ & $56 \mathrm{H}$ & $27 \mathrm{H}$ \\
\hline 46 & W & $57 \mathrm{H}$ & $3 \mathrm{AH}$ \\
\hline 47 & $X$ & $58 \mathrm{H}$ & $2 \mathrm{DH}$ \\
\hline 48 & $\mathrm{Y}$ & $59 \mathrm{H}$ & $3 \mathrm{DH}$ \\
\hline 49 & Z & $5 \mathrm{AH}$ & $35 \mathrm{H}$ \\
\hline 50 & $\mathrm{a}$ & $61 \mathrm{H}$ & $01 \mathrm{H}$ \\
\hline 51 & b & $62 \mathrm{H}$ & $03 \mathrm{H}$ \\
\hline 52 & $\mathrm{c}$ & $63 \mathrm{H}$ & $09 \mathrm{H}$ \\
\hline 53 & d & $64 \mathrm{H}$ & $19 \mathrm{H}$ \\
\hline 54 & e & $65 \mathrm{H}$ & $11 \mathrm{H}$ \\
\hline 55 & $\mathrm{f}$ & $66 \mathrm{H}$ & $\mathrm{OBH}$ \\
\hline 56 & g & $67 \mathrm{H}$ & $1 \mathrm{BH}$ \\
\hline 57 & $\mathrm{~h}$ & $68 \mathrm{H}$ & $13 \mathrm{H}$ \\
\hline 58 & $\mathrm{i}$ & $69 \mathrm{H}$ & $0 \mathrm{AH}$ \\
\hline 59 & $\mathrm{j}$ & $6 \mathrm{AH}$ & $1 \mathrm{AH}$ \\
\hline 60 & $\mathrm{k}$ & $6 \mathrm{BH}$ & $05 \mathrm{H}$ \\
\hline 61 & 1 & $6 \mathrm{CH}$ & $07 \mathrm{H}$ \\
\hline
\end{tabular}




\begin{tabular}{|l|l|l|l|}
\hline 24 & A & $41 \mathrm{H}$ & $01 \mathrm{H}$ \\
\hline 25 & B & $42 \mathrm{H}$ & $03 \mathrm{H}$ \\
\hline 26 & C & $43 \mathrm{H}$ & $09 \mathrm{H}$ \\
\hline 27 & D & $44 \mathrm{H}$ & $19 \mathrm{H}$ \\
\hline 28 & E & $45 \mathrm{H}$ & $11 \mathrm{H}$ \\
\hline 29 & F & $46 \mathrm{H}$ & $0 \mathrm{BH}$ \\
\hline 30 & G & $47 \mathrm{H}$ & $1 \mathrm{BH}$ \\
\hline 31 & $\mathrm{H}$ & $48 \mathrm{H}$ & $13 \mathrm{H}$ \\
\hline 32 & I & $49 \mathrm{H}$ & $0 \mathrm{AH}$ \\
\hline 33 & $\mathrm{~J}$ & $4 \mathrm{AH}$ & $1 \mathrm{AH}$ \\
\hline 34 & $\mathrm{~K}$ & $4 \mathrm{BH}$ & $05 \mathrm{H}$ \\
\hline 35 & L & $4 \mathrm{CH}$ & $07 \mathrm{H}$ \\
\hline 36 & M & $4 \mathrm{DH}$ & $0 \mathrm{DH}$ \\
\hline 37 & $\mathrm{~N}$ & $4 \mathrm{EH}$ & $1 \mathrm{DH}$ \\
\hline 38 & O & $4 \mathrm{FH}$ & $15 \mathrm{H}$ \\
\hline
\end{tabular}

\begin{tabular}{|l|l|l|l|}
\hline 62 & $\mathrm{~m}$ & $6 \mathrm{DH}$ & $0 \mathrm{DH}$ \\
\hline 63 & $\mathrm{n}$ & $6 \mathrm{EH}$ & $1 \mathrm{DH}$ \\
\hline 64 & o & $6 \mathrm{FH}$ & $15 \mathrm{H}$ \\
\hline 65 & $\mathrm{p}$ & $70 \mathrm{H}$ & $0 \mathrm{FH}$ \\
\hline 66 & q & $71 \mathrm{H}$ & $1 \mathrm{FH}$ \\
\hline 67 & r & $72 \mathrm{H}$ & $17 \mathrm{H}$ \\
\hline 68 & s & $73 \mathrm{H}$ & $0 \mathrm{EH}$ \\
\hline 69 & $\mathrm{t}$ & $74 \mathrm{H}$ & $1 \mathrm{EH}$ \\
\hline 70 & u & $75 \mathrm{H}$ & $25 \mathrm{H}$ \\
\hline 71 & v & $76 \mathrm{H}$ & $27 \mathrm{H}$ \\
\hline 72 & w & $77 \mathrm{H}$ & $3 \mathrm{AH}$ \\
\hline 73 & x & $78 \mathrm{H}$ & $2 \mathrm{DH}$ \\
\hline 74 & y & $79 \mathrm{H}$ & $3 \mathrm{DH}$ \\
\hline 75 & z & $7 \mathrm{AH}$ & $35 \mathrm{H}$ \\
\hline & & & \\
\hline
\end{tabular}

Pada saat akan menjalankan alat bantu komunkasi tunanetra dan tunarungu dengan menggunakan kode braille dan pengenalan suara per-karakter, maka komputer harus dinyalakan terlebih dahulu lalu memasang penghubung untuk koneksi antara komputer dengan alat tersebut dan memasang microphone. Setelah semuanya terpasang dengan baik, maka alat tersebut sudah dapat dijalankan dan proses pengenalan suara per-karakter sudah dapat berjalan. Untuk penyandang tunarungu dapat mengetikkan karakter di komputer dengan menggunakan software yang ada, karakter atau kalimat tersebut dikonversi menjadi bilangan hexa ASCII. Setelah menjadi bilangan hexa maka karakter itu siap dikirimkan ke mikrokontroler AT89C51 melalui port serial sebagai antarmuka. Di dalam mikrokontroler bilangan hexa ASCII tersebut dikonversi lagi menjadi kode braille.

Kode braille yang didapatkan dari hasil konversi di dalam mikrokontroler tersebut berupa bilangan hexa (kode braille), yang kemudian digunakan mikrokontroler sebagai $\mathrm{V}_{\mathrm{IN}}$ untuk mengatur solenoid melalui driver solenoid IC ULN2803 untuk menaikkan tombol maupun menurunkan tombol. Tombol yang naik tersebut yang digunakan oleh tunanetra dalam membaca karakter. Untuk penyandang tunanetra dapat mengucapkan kata per-karakter yang akan dikenali oleh software yang telah dibuat dan hasilnya akan ditampilkan pada aplikasi. 


\section{Rancangan Software Sistem}

Software (perangkat lunak) dibuat menggunakan Dephi 6.0. Pada Gambar 6 ditunjukkan Diagram alir software pada sisi komputer ketika dilakukan pengenalan suara, sedangkan pada Gambar 7 ditunjukkan diagram alir pada sisi mikrokontroler.

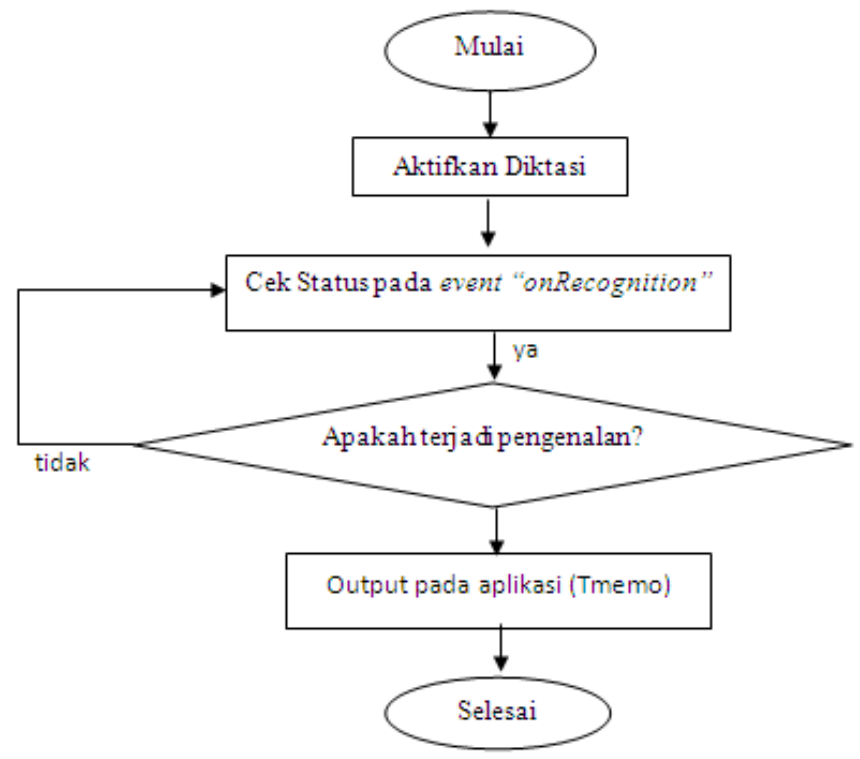

Gambar 6. Diagram Alir Program Pengenalan Suara Pada Sisi Komputer 


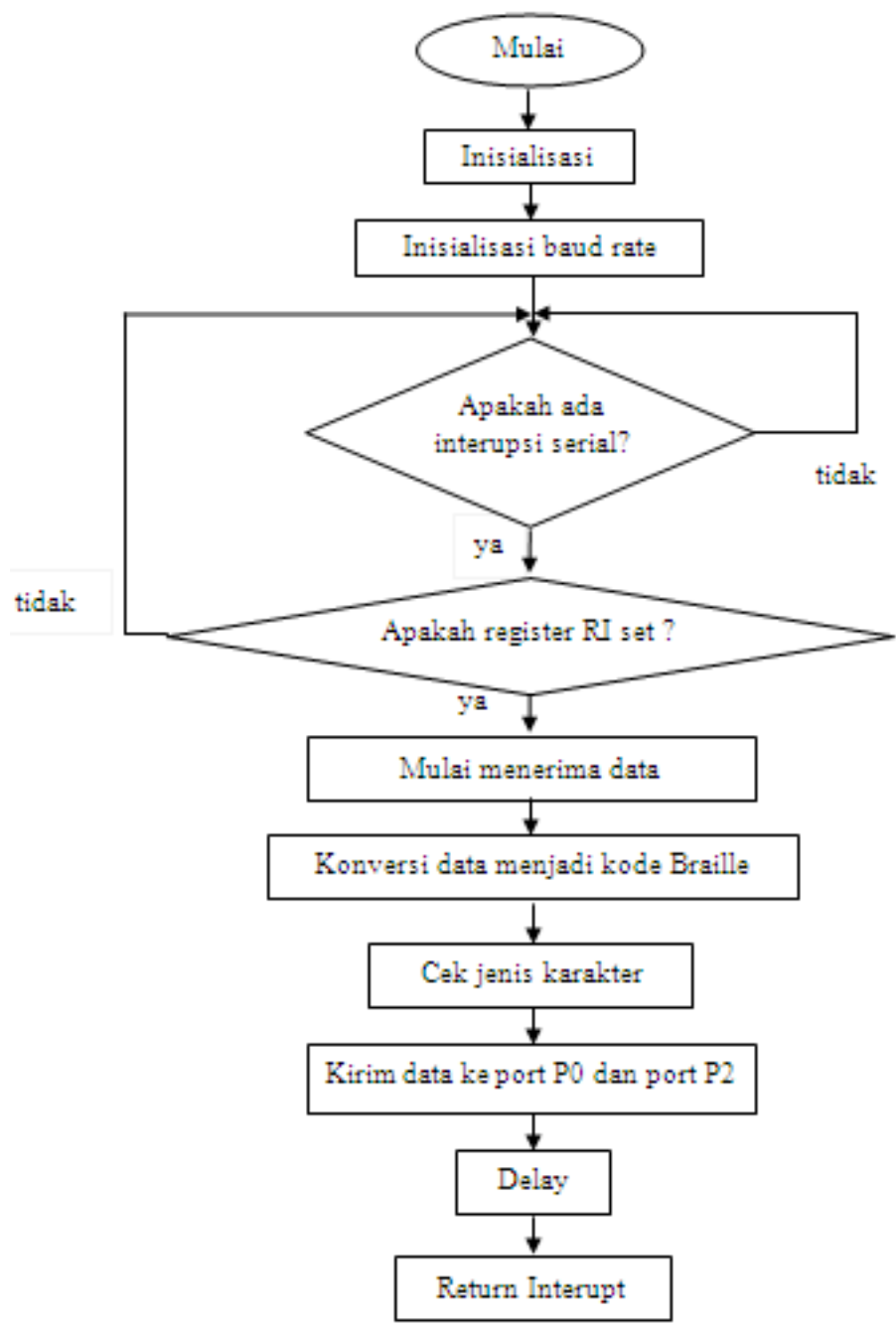

Gambar 7. Diagram Alir Program pada sisi Mikrokontroler

Hasil desain tampilan menu program yang dirancang menggunakan software Dephi 6.0 dapat dilihat pada Gambar 8. 


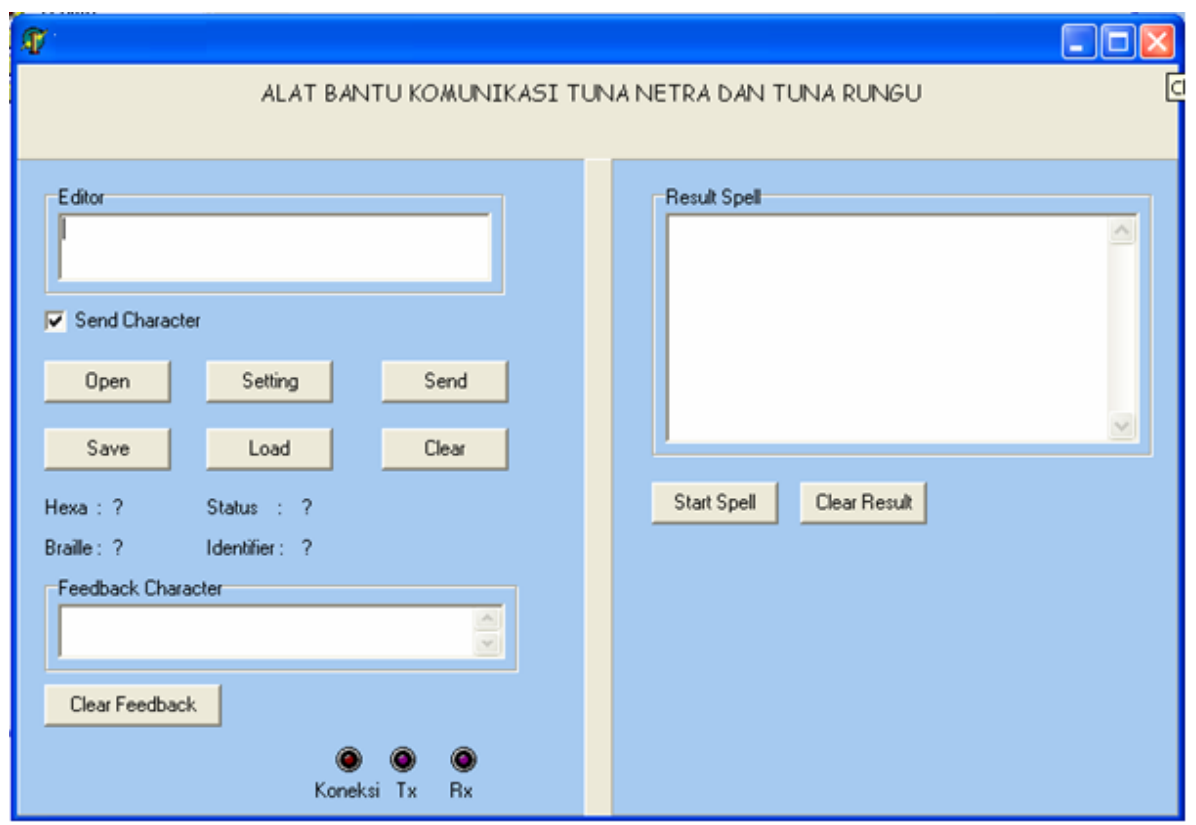

Gambar 8. Rancangan Software untuk Tampilan Menu

Keterangan Gambar 8:

Send : Mengirimkan string yang telah dipecah per-karakter ke alat melalui port serial.

Open : Akan mengaktifkan port serial ketika tombol open ditekan.

Clear : Menghapus semua karakter yang telah di ketik pada memo.

Setup : Akan membuka kotak dialog setting port serial.

Save : Akan menyimpan pengaturan port serial.

Load : Akan memanggil setting port serial yang telah disimpan.

Start Spell : Mempersilakan pada penyandang tunanetra untuk mulai berbicara per-karakter.

Clear Result : Menghapus semua karakter yang telah di ucapkan oleh penyandang tunanetra.

Clear Feedback : Menghapus karakter yang dikirimkan kembali oleh mikrokontroler.

Label Hexa : : Menunjukkan nilai hexadecimal dari karakter.

Label Braille : Menunjukkan nilai kode Braille dari karakter.

Label Status : Menunjukkan jenis dari karakter yang dikirim.

Label Identifier : Menunjukkan nilai identifier dari karakter yang menunjukkan jenis karakter kepada tunanetra.

Lampu Koneksi : Menunjukkan bahwa alat telah terkoneksi ke komputer.

Lampu Tx : Lampu ini akan menyala saat terjadi pengiriman data.

Lampu Rx : : Lampu ini akan menyala saat terjadi penerimaan data.

Pengenalan suara per-karakter ini, menggunakan diktasi. Mode diktasi ini menggunakan metode pemisahan kata dengan cara discrete speech, speaker dependent, Pencocokan kata whole word dan large vocabulary. 
Discrete speech, mengharuskan untuk mengucapkan kalimat secara terpenggal dengan adanya jeda sejenak diantara kata. Jeda tersebut digunakan oleh sistem untuk mendeteksi awal dan akhir sebuah kata. Speaker dependent sistem membutuhkan pelatihan suara untuk setiap pengguna yang akan menggunakan sistem tersebut. Sistem tidak dapat mengenali suara pengguna yang belum pernah melakukan pelatihan. Pencocokan kata dengan whole word, sistem akan mencari di basis data kata yang sama persis dengan kata hasil ucapan. Algoritma pengenalan suara dapat dilihat pada lampiran B.

Diktasi dengan cara di atas membutuhkan minimal 8MB RAM dan processor Pentium. Sedangkan untuk sistem operasi yang diperlukan agar sistem dapat berjalan adalah Windows 95, Windows NT 3.5 dan yang lebih besar lagi (Windows XP).

Pengujian pengiriman karakter dari sisi komputer (sisi tunarungu) ke sisi tunanetra menunjukkan semua karakter dapat dikonversikan menjadi Kode Braille.

Pengujian pengenalan suara menggunakan diktasi ini memakai sampel dua orang pria dan dua orang wanita. Jumlah huruf dan tanda baca yang diuji coba ada 28 buah. Pengujian dilakukan dengan tanpa pelatihan dan pengujian dengan pelatihan.

- Hasil Pengujian Pengenalan Suara Tanpa Pelatihan

Huruf dan tanda baca yang diujikan sebanyak 28 macam

\begin{tabular}{|l|l|l|l|l|}
\hline & Pria ke-1 & Pria ke-2 & Wanita ke-1 & Wanita ke-2 \\
\hline Keakuratan & $35,714 \%$ & $10,714 \%$ & $39,285 \%$ & $32,142 \%$ \\
\hline
\end{tabular}

- Hasil Pengujian Pengenalan Suara Dengan Pelatihan Huruf dan tanda baca yang diujikan sebanyak 28 macam

\begin{tabular}{|l|l|l|l|l|}
\hline & Pria ke-1 & Pria ke-2 & Wanita ke-1 & Wanita ke-2 \\
\hline Keakuratan & $78,571 \%$ & $67,857 \%$ & $71,428 \%$ & $71,428 \%$ \\
\hline
\end{tabular}

Dari hasil pengujian di atas dapat dilakukan analisis sebagai berikut:

- Sebelum melakukan pelatihan, kesalahan pengenalan yang terjadi dan huruf yang tidak dikenali sangat banyak yang dikarenakan speech engine yang digunakan bukan khusus untuk bahasa Indonesia. Ketepatan cara pengucapan dari pembicara juga sangat mempengaruhi hasil yang didapat karena aplikasi pengenalan suara yang dibuat ini menggunakan cara diktasi yang salah satu metodenya adalah tergantung kepada pembicara (speaker dependant).

- Setelah melakukan pelatihan, karakter yang tidak dapat dikenali oleh sistem dikarenakan perbedaan pengucapan karakter pada saat pelatihan dan pada saat melakukan pengenalan suara. Faktor kesamaan antara huruf yang diucapkan dengan huruf lain yang pada saat pelatihan dan kata lain dalam bahasa Inggris juga sangat mempengaruhi keberhasilan dari pengenalan.

- Kesalahan yang terjadi juga dapat disebabkan oleh frekuensi suara manusia yang berbeda-beda dan noise dari lingkungan sekitar.

- Selisih persentase rata-rata setelah dan sebelum melakukan pelatihan adalah:

Selisih Rata-rata $=$ Rata-rata2 - Rata-rata $1=72,321 \%-29,463 \%=42,858 \%$

- Dari setiap percobaaan yang dilakukan pada percobaan yang menggunakan empat sample pembicara, karakter yang selalu berhasil dikenali adalah karakter a, c, f, h, j, k, l, m, n, o, p, q, v, w, 
y, z, titik dan koma. Pada percobaan berulang pada pria yang sama, karakter yang selalu berhasil dikenali adalah karakter a, c, e, f, g, h, i, j, k, l, p, r, s, t, x, z, titik dan koma.

- Melihat perbedaan yang cukup besar dari hasil yang didapat maka untuk meminimalkan kesalahan perlu dilakukan pelatihan terlebih dahulu.

- Perbedaan persentase pada pria dan wanita yang didapat sebelum melakukan pelatihan dan setelah melakukan pelatihan dikarenakan ketepatan cara pengucapan dari pembicara saat melakukan pelatihan dan saat melakukan diktasi karena salah satu metode diktasi yang digunakan adalah speaker dependant (tergantung pada pembicara). Jika pengucapan berbeda maka kemungkinan kesalahan yang terjadi akan semakin besar.

- Kondisi dari pembicara sangat mempengaruhi keakuratan, karena suara akan berbeda disaat pembicara sedang dalam keadaan sehat dan sakit, khususnya sakit yang berhubungan dengan pita suara.

\section{PENUTUP}

Alat bantu komunikator tunarungu dan tunanetra dapat dirancang dan direalisasikan. Sistem dapat mengirimkan data karakter dari sisi komputer (sisi tunarungu) ke sisi tunanetra dengan baik di mana semua karakter huruf kapital, huruf kecil maupun tanda baca atau karakter khusus dapat dikonversikan menjadi Kode Braille.

Dalam pengujian pengiriman sinyal dari sisi tunanetra ke sisi tunarungu, pengenalan pola suara tingkat keberhasilan pada 4 sample (dua pria dan dua wanita) rata-rata tingkat keberhasilannya sebesar $71,428 \%$ dan pada percobaan berulang pada pria yang sama tingkat keberhasilannya sebesar 79,28\%. Tingkat keberhasilan pada pengenalan suara dapat dipengaruhi beberapa faktor, yaitu perbedaan suara pada saat melakukan pelatihan dan pada saat melakukan diktasi, noise dari lingkungan dan kualitas dari microphone yang digunakan.

\section{DAFTAR PUSTAKA}

[1] Ager, Simon. Braille. Diakses tanggal 16 September 2008 dari World Wide Web: http:// www.omniglot.com/writing/braille.htm

[2] Amundsen, Michael C. (1996). MAPI, SAPI, and TAPI Developer's Guide. Indianapolis: Sams Publishing. Diakses pada tanggal 01 Januari 2009 dari World Wide Web: http:// www.ssuet.edu.pk/taimoor/books/0-672-30928-9/.

[3] Bergamini, Alex. (2001). Speech Part 2 - How to Add Simple Dictation Speech Recognition to Your Delphi Apps. Diakses pada tanggal 12 Januari 2009 dari World Wide Web: http://www.delphi3000.com/articles/article_2629.asp?SK=.

[4] http://alldatasheet.com. Diakses pada tanggal 16 September 2008.

[5] http://id.wikipedia.org/wiki/Braille.htm. Diakses pada tanggal 19 September 2008.

[6] Iswanto. (2008). Antarmuka Port Paralel dan Port Serial dengan Delphi 6 Compatible Sistem Operasi Windows. Yogyakarta: Gava media.

[7] Long, Brian. Speech Synthesis \& Speech Recognition. Diakses pada tanggal 05 Januari 2009 dari http://www.blong.com/Conferences/ DCon2002/Speech/Speech.htm.

[8] Mujahidin. (2005). Serial Port Computer \& Pemrogramannya Dengan VB 6.0. Diakses pada tanggal 14 Januari 2009 dari http://www.iddhien.com. 
[9] Noertjahyana, A., \& Adipranata, R. (2003). Implementasi Sistem Pengenalan Suara Menggunakan SAPI 5.1 dan Delphi 5. Diakses pada tanggal 12 Januari 2009 dari World Wide Web: puslit.petra.ac.id/ puslit/journals/ pdf.php?PublishedID= INF03040208 